\title{
Colorectal cancer screening behaviors of general surgeons and first-degree family members: a survey-based study
}

Suleyman Utku Celik, Hasan Gorkem Cay², Ersin Bayrakdar², Aysima Ince², Esra Nur Ince², Yasemin Celik², Yunus Emre Yucel $^{2}$, Mehmet Ali Koc ${ }^{2}$, Siyar Ersoz ${ }^{2}$ and Cihangir Akyol ${ }^{2^{*}}$ (D)

\begin{abstract}
Background: Colorectal cancer (CRC) screening rates are low in the general population and among health care providers. The aim of this study was to evaluate the CRC screening practices of general surgeons who provide specialized diagnostic testing and CRC treatment and to examine the CRC screening behaviors of their first-degree family members.

Methods: A cross-sectional survey was conducted among general surgeons who attended the 21st National Surgical Congress in Turkey held from April 11th to 15th, 2018. The survey included items on demographics, screening-related attitude, CRC screening options, barriers to CRC screening, and surgeons' annual volumes of CRC cases.

Results: A total of 530 respondents completed the survey. Almost one-third of the responding surgeons (29.4\%, $n=156)$ were aged over 50 years, among whom approximately half $(47.1 \%, n=74)$ reported having undergone CRC screening and preferring a colonoscopy as the screening modality (78.4\%). Among general surgeons aged 50 years and older, high-volume surgeons ( $\geq 25$ CRC cases per year) were more likely to undergo screening compared with low-volume surgeons ( $<25$ CRC cases per year). The respondents aged below 50 years reported that $56.1 \%$ ( $n=$ 210) of their first-degree relatives were up-to-date with CRC screening, mostly with colonoscopy. Compared to lowvolume surgeons aged below 50 years, high-volume surgeons' first-degree relatives were more likely to be up-todate with CRC screening.

Conclusion: The survey results demonstrated that routine screening for CRC among surgeons and/or their firstdegree relatives is currently not performed at the desired level. However, high-volume surgeons are more likely to participate in routine screening.
\end{abstract}

Keywords: Attitude, Behavior, Colorectal cancer, General surgeons, Screening

\section{Background}

Colorectal cancer (CRC) screening is performed to diagnose early-stage CRC and precancerous lesions in asymptomatic individuals. Currently, the US MultiSociety Task Force of Colorectal Cancer and US Preventive Services Task Force (USPSTF) recommend CRC

\footnotetext{
* Correspondence: cihangirakyol@gmail.com

This paper was presented as a poster presentation at 13th Scientific and

Annual Meeting of the European Society of Coloproctology, Nice, France, 2628 September 2018

${ }^{2}$ Department of General Surgery, Ankara University School of Medicine,

Ankara, Turkey

Full list of author information is available at the end of the article
}

screening to be initiated at 50 years of age and to continue the screenings until 75 years of age for individuals at average risk of the disease $[1,2]$. Furthermore, the USPSTF recommends screening for eligible individuals using stool-based screening tests such as fecal immunochemical tests (annually), guaiac-based fecal occult blood tests (FOBTs) (annually), and multitarget stool DNA tests (every 1 or 3 years) or tests that directly and effectively visualize the colon, including colonoscopy (every 10 years), flexible sigmoidoscopy (every 5 years), and computed tomography colonography (every 5 years) $[1,2]$. In 2014, the National Colorectal Cancer Roundtable,

(c) The Author(s). 2019 Open Access This article is distributed under the terms of the Creative Commons Attribution 4.0 International License (http://creativecommons.org/licenses/by/4.0/), which permits unrestricted use, distribution, and reproduction in any medium, provided you give appropriate credit to the original author(s) and the source, provide a link to the Creative Commons license, and indicate if changes were made. The Creative Commons Public Domain Dedication waiver (http://creativecommons.org/publicdomain/zero/1.0/) applies to the data made available in this article, unless otherwise stated. 
co-founded by the American Cancer Society (ACS) and the Centers for Disease Control and Prevention, announced an initiative named " $80 \%$ by 2018." This initiative set the major public health goal of screening $80 \%$ of eligible adults aged 50 years and older by 2018 to reduce the incidence and mortality rates from CRC by over 20 and 33\%, respectively, by 2030 [3, 4]. Despite the relatively high availability of tests, widespread campaigns, and educational efforts, a significant proportion of adults aged $50-70$ years remain unscreened; in 2016 , only $67.3 \%$ of eligible adults were screened for CRC in the United States [2, 5, 6]. Overall, CRC screening rates are unacceptably low, especially in undeveloped and developing countries as well as in most European countries [6-8].

General surgeons involved in screening, management, and follow-up of CRC treatment as well as in policy initiatives, national cancer prevention campaigns, and community awareness activities might be eligible for CRC screening and/or have eligible family members aged 50 years and older. However, CRC screening rates are low in the general population and among health care providers $[9,10]$. The aim of this study was to evaluate the CRC screening practices of general surgeons who provide specialized diagnostic testing and CRC treatment and to examine the CRC screening behaviors of their first-degree family members.

\section{Methods}

\section{Individuals}

A cross-sectional survey was administered to each registered Turkish general surgeon attending the 21st National Surgical Congress, the largest and most representative national meeting of general surgeons, at Antalya, Turkey (April 11-15, 2018). Surgeons who did not complete the questionnaire were excluded from the study.

\section{Questionnaire}

Survey questions related to CRC screening practices were designed in accordance with the USPSTF recommendations [2]. To assess CRC screening behaviors, the $\mathrm{CRC}$ screening status of the surgeons and their relatives was evaluated.

The questionnaire included closed-ended questions. The first part of the questionnaire consisted of the demographic details of the surgeons, which included age, gender, workplace, academic title, and annual volumes of CRC cases. Here, the respondents were divided into two groups according to their age: (1) aged below 50 years and (2) aged 50 years and older. In the second part, for the surgeons assigned to Group 1, the questionnaire included questions on their attitude related to screening for their first-degree relatives (mother or father) and their screening options; for the surgeons assigned to Group 2, the questionnaire comprised questions regarding CRC screening for themselves, barriers to screening, and family history.

Content validity of the questionnaire was assessed by five experts in the field of colorectal surgery to ensure its suitability for the study, to edit questions for clarity and to remove redundant questions. Then, the questionnaire was piloted with a sample of 10 general surgeons from the researchers' institute to ensure the clarity of its items.

\section{Surgeon volume}

A surgeon performing 25 or more CRC operations annually was classified as a high-volume surgeon and a surgeon who performed on average fewer than 25 cases annually was classified as a low-volume surgeon. This categorization was made in accordance with recent studies [11-13].

\section{Data collection}

Data were collected with self-administered, anonymous, multiple-choice questionnaires (Additional file 1). The information gathering instrument created by the research team was a web-based survey with a total of eleven questions.

The final instrument was delivered to the participants via a web-based survey platform after obtaining permission from the chair of the congress committee. In addition to recurring emails, reminders were sent to participants at regular intervals if they did not complete the survey within the allocated time. A maximum of two reminders were sent to nonresponders, 1 day and 3 days after the initial invitation. After 4 days, the survey was set offline and the data were locked.

\section{Statistical analysis}

Descriptive analysis was used to assess the demographic details of the study participants. Data were expressed as frequencies (\%) for categorical variables. The differences in terms of proportion between the groups were compared using the chi-square or Fisher's exact test, where appropriate. A $p$-value of $<0.05$ was considered statistically significant. Missing data were handled by listwise deletion for each analysis. All statistical data were analyzed using the Statistical Package for the Social Sciences program (version 16.0 for Windows; Chicago, IL).

\section{Ethical approval}

This study was approved by the Ankara University School of Medicine Undergraduate Student Researches Ethics Committee (approval number: 72189195-050.03.04E.6039) and was carried out in accordance with the 1964 Helsinki Declaration and its later amendments. In 
addition, written informed consent for publication of individuals' clinical details was obtained.

\section{Results}

The survey was conducted among 553 general surgeons. Twenty-three surgeons who did not complete the questionnaire were excluded from the study. Therefore, a total of 530 questionnaires were completed, with an overall response rate of $95.8 \%$. The respondents were divided into two groups according to their age: (1) aged below 50 years (Group 1, $n=374$ ) and (2) aged 50 years and older (Group 2, $n=156$ ). Table 1 presents the CRC screening data for the first-degree relatives of the surgeons aged below 50 years, whereas Table 2 presents the self-screening data of the surgeons aged 50 years and older.

The majority of the surgeons were males $(n=484$, 91.3\%). Among the general surgeons aged 50 years and older, $47.1 \%(n=74)$ had previously undergone screening for CRC in a timely manner. The CRC screening methods preferred by surgeons included colonoscopy and FOBT (78.4 and 17.6\%, respectively). Surgeons who had been screened for CRC exhibited no differences in terms of sex $(p=1.000)$, workplace $(p=0.807)$, or academic title $(p=0.067)$ compared with those who had not been screened. However, surgeons handling over 25 CRC cases annually (high-volume surgeons) were more likely to undergo screening for themselves compared with those handling less than $25 \mathrm{CRC}$ cases annually (low-volume surgeons) (60.0\% vs. $40.6 \%, p=0.020)$. Expectedly, surgeons with a family history of CRC were more likely to adhere to screening recommendations than those without a family history $(p=0.003)$. The main barriers to undergoing CRC screening included procrastination owing to work intensity (63.4\%), the belief that CRC screening is not necessary $(21.9 \%)$, and anxiety or fear related to CRC screening (14.7\%).

Among the 374 surgeons aged below 50 years, slightly more than half $(56.1 \%)$ reported that at least one of their first-degree family members were up-to-date with the CRC screening recommendations. Colonoscopy was the most preferred $(78.1 \%)$ screening tool. Notably, there were no significant differences in terms of $\operatorname{sex}(p=$ $0.066)$, workplace $(p=0.853)$, and academic title $(p=$ 0.179 ) between surgeons whose first-degree relatives had undergone CRC screening and those whose relatives had not undergone the screening. Similarly, compared to low-volume surgeons, high-volume surgeons' firstdegree relatives were more likely to be up-to-date with CRC screening of any type $(51.9 \%$ vs. $64.1 \%, p=0.023)$.

\section{Discussion}

Although CRC screening rates are modestly improving, we are still a long way from the National Colorectal Cancer Roundtable's goal of $80 \%$ of adults aged 50 and older being regularly screened for CRC by 2018 [3, 4]. Unfortunately, the data from this study revealed that more than half of surveyed surgeons aged 50 years and older had not previously been screened for CRC in a timely manner even though national CRC screening policies and guidelines may be in place. Despite differences in the perceived barriers between surgeons and the

Table 1 Screening characteristics of first-degree relatives of surgeons younger than 50 years of age

\begin{tabular}{|c|c|c|c|}
\hline \multirow[t]{2}{*}{ Surgeon characteristics } & \multicolumn{2}{|c|}{ CRC screening for surgeons' first-degree relatives } & \multirow[t]{2}{*}{$P$-value } \\
\hline & No $(n=164)$ & Yes $(n=210)$ & \\
\hline \multicolumn{4}{|l|}{ Sex, n } \\
\hline Male & $141(42.2 \%)$ & $193(57.8 \%)$ & \multirow[t]{2}{*}{0.066} \\
\hline Female & $23(57.5 \%)$ & $17(42.5 \%)$ & \\
\hline \multicolumn{4}{|l|}{ Workplace, $\mathrm{n}$} \\
\hline State hospital & $48(44.4 \%)$ & $60(55.6 \%)$ & \multirow[t]{4}{*}{0.853} \\
\hline Private hospital & $19(44.2 \%)$ & $24(55.8 \%)$ & \\
\hline Training and research hospital & $58(46.0 \%)$ & $68(54.0 \%)$ & \\
\hline University hospital & $39(40.2 \%)$ & $58(59.8 \%)$ & \\
\hline \multicolumn{4}{|l|}{ Academic title, $\mathrm{n}$} \\
\hline Specialist & $119(46.9 \%)$ & $135(53.1 \%)$ & \multirow[t]{3}{*}{0.179} \\
\hline Associate professor & $36(36.0 \%)$ & $64(64.0 \%)$ & \\
\hline Professor & $9(45.0 \%)$ & $11(55.0 \%)$ & \\
\hline \multicolumn{4}{|l|}{ Volume of CRC cases, $\mathrm{n}$} \\
\hline Low volume ( $<25$ cases) & $117(48.1 \%)$ & $126(51.9 \%)$ & \multirow[t]{2}{*}{0.023} \\
\hline High volume ( $\geq 25$ cases) & 47 (35.9\%) & $84(64.1 \%)$ & \\
\hline
\end{tabular}


Table 2 Screening characteristics of surgeons aged 50 years and older

\begin{tabular}{|c|c|c|c|}
\hline \multirow[t]{2}{*}{ Surgeon characteristics } & \multicolumn{2}{|c|}{ CRC screening status of the surgeons } & \multirow{2}{*}{$\begin{array}{l}P \text { - } \\
\text { value }\end{array}$} \\
\hline & No $(n=82)$ & Yes $(n=74)$ & \\
\hline \multicolumn{4}{|l|}{ Sex, n } \\
\hline Male & $79(52.7 \%)$ & $71(47.3 \%)$ & \multirow[t]{2}{*}{1.000} \\
\hline Female & $3(50.0 \%)$ & $3(50.0 \%)$ & \\
\hline \multicolumn{4}{|l|}{ Workplace, n } \\
\hline State hospital & $20(55.6 \%)$ & $16(44.4 \%)$ & \multirow[t]{4}{*}{0.807} \\
\hline Private hospital & $15(50.0 \%)$ & $15(50.0 \%)$ & \\
\hline Training and research hospital & $24(57.1 \%)$ & $18(42.9 \%)$ & \\
\hline University hospital & $23(47.9 \%)$ & $25(52.1 \%)$ & \\
\hline \multicolumn{4}{|l|}{ Academic title, $\mathrm{n}$} \\
\hline Specialist & $45(60.0 \%)$ & $30(40.0 \%)$ & \multirow[t]{3}{*}{0.067} \\
\hline Associate professor & $11(61.1 \%)$ & $7(38.9 \%)$ & \\
\hline Professor & $26(41.3 \%)$ & $37(58.7 \%)$ & \\
\hline \multicolumn{4}{|l|}{ Volume of CRC cases, $\mathrm{n}$} \\
\hline Low volume ( $<25$ cases) & $60(59.4 \%)$ & $41(40.6 \%)$ & \multirow[t]{2}{*}{0.020} \\
\hline High volume ( $\geq 25$ cases) & $22(40.0 \%)$ & $33(60.0 \%)$ & \\
\hline \multicolumn{4}{|l|}{ Family history, n } \\
\hline No & $76(57.6 \%)$ & $56(42.4 \%)$ & \multirow[t]{2}{*}{0.003} \\
\hline Yes & $6(25.0 \%)$ & 18 (75.0\%) & \\
\hline
\end{tabular}

CRC Colorectal cancer

general population, our results are important in the context of understanding the barriers to CRC screening. Understanding the reason why health care providers or surgeons, who routinely provide screening options to their patients and have a broad knowledge of CRC and its risks, do not follow the recommendations for routine screening for themselves is as valuable as other policies and campaigns developed for CRC screening. The primary purpose of this study was to evaluate the CRC screening practices of general surgeons and their firstdegree family members. We also assessed the main barriers to routine $\mathrm{CRC}$ screening for themselves.

Globally, CRC is the third most commonly diagnosed cancer among males and females $[14,15]$. The incidence and mortality rates of CRC have been decreasing over the past several decades due to changes in related risk factors, an increase in routine screening facilitating precursor lesion removal, and advances in surgical and medical management. Because most CRC develops slowly from removable precancerous lesions known as adenomas, which can take up to 10 years or more to become malignant, detection of early-stage CRC has a good prognosis [16, 17]. Therefore, CRC is a suitable candidate for screening to markedly reduce the incidence and mortality of the disease $[1,5,17,18]$. Furthermore, CRC screening by any currently available modality appears to be more cost-effective than not performing screening and the cost burden of CRC treatment $[1,18]$.
Regular CRC screening is vital for the early detection of precursor lesions in asymptomatic individuals aged 50-75 years [1, 2]. Numerous CRC deaths could also be prevented through increased population-based screening programs $[1,5,14,17,18]$. Although multiple screening options are available, there is no evidence that one screening test is superior to another; in fact, all tests have a comparable ability to reduce CRC mortality rates via early detection, provided average-risk adults adhere to the steps mentioned in the screening guidelines at the appropriate time intervals $[17,19,20]$. However, despite the availability of these tests, widespread recommendations for screening, and the presence of screening programs, nearly one-quarter of eligible adults have never been screened for CRC; in 2016, only $67.3 \%$ of ageappropriate individuals were updated about screening in the United States $[2,5,6]$. This statistic is not better in other countries; in fact, it is worst in developing countries. The screening rates of European countries range from 20 to $68 \%$, which is far from the targeted goals and desirable standards $[7,21]$.

Provider adherence to evidence-based screening guidelines is crucial for CRC prevention and control, regardless of health policy initiatives and campaigns [22]. Provider recommendations and guidance can also improve compliance with CRC screening $[1,6]$. In Turkey, general surgeons and gastroenterologists are the major providers of gastrointestinal (GI) endoscopy and other 
specialized screening options. Although many studies emphasized that CRC screening is recommended to average-risk adults by most health care providers (6595\%), personal routine CRC screening rates are low in those deemed eligible for screening $[9,10,23,24]$. In a study by Terhaar Sive Droste et al., this difference was highlighted to be more pronounced when compared between GI specialists (gastroenterologists and gastrointestinal surgeons) and general practitioners (GPs). It was found that screening for CRC was strongly supported by Dutch GI specialists and less by GPs. Moreover, a significant difference was found in the preferred personal screening method among them. While screening with colonoscopy was favored by $97 \%$ of GI specialists, only $27 \%$ of GPs preferred this method [25].

To the best of our knowledge, this study is the first in the English literature to examine general surgeons' personal routine CRC screening practices. The study focused on the personal or first-degree relatives' CRC screening practices of 530 general surgeons who routinely provide screening options to their patients at average risk for CRC in Turkey. In the present study, we found that less than half $(47.1 \%)$ of the surgeons aged 50 years and older had previously been screened for CRC in a timely manner, and only half $(56.1 \%)$ of the surgeons under 50 years of age reported that their firstdegree family members were up-to-date with CRC screening. Similarly, in a study conducted by Rim et al., which included 109 health care professionals such as family physicians, internists, physician assistants, and nurse practitioners aged over 50 years, just over half $(60 \%)$ had been screened for CRC and slightly less than half (48\%) were not up-to-date with CRC screening recommendations [9]. Our data also showed that surgeons with a positive family history of CRC were more motivated to screen for CRC. However, the workplace or academic title of the surgeons had no impact on the routine screening practice of the surgeons or their family members.

It is well known that surgical specialization and highvolume practice are both associated with better outcomes for CRC surgery. However, there is no definite cut-off value of surgeon volume at which to decide whether a surgeon is a high- or low-volume surgeon. In addition, this value changes according to country, city, and hospital [11-13]. In our study, this categorization was made in accordance with recent studies, and the surgeons were grouped into two categories (low volume: $<25$ cases; high volume: $\geq 25$ cases). Our data showed that compared with low-volume surgeons aged 50 years and older, highvolume surgeons were more likely to adhere to screening recommendations and similarly, compared with lowvolume surgeons under 50 years of age, the first-degree relatives of high-volume surgeons were significantly more likely to be up-to-date with CRC screening. These results suggest that general surgeons familiar with CRC cases or specifically interested in colorectal surgery may recognize the benefits of early screening for CRC in particular compared with those who are not.

For the general population, poor awareness of CRC and screening programs, characteristics of screening tests such as patient preparation or complications for colonoscopy and the potential to overlook cancer or a false positive result for FOBT, lack of time, and financial issues are important factors that affect the attendance rate of CRC screening programs [18, 23, 26]. However, the perceived barriers for health care providers are significantly different from the general population. In this study, the main barrier to screening was found to be procrastination owing to work intensity (63.4\%); the other barriers were the belief that CRC screening is not necessary, worry about the results, anxiety, and fear about complications. In addition, while female physicians are far more likely to recommend screening compared to their male counterparts [24, 27], female surgeons at average risk for CRC in our study were not more likely to be up-to-date with CRC screening guidelines than males. Based on our survey results, it is difficult to explain the lower screening rates of general surgeons and their first-degree family members. Although not exactly the same, the general population and surgeons probably have similar concerns with regard to CRC screening. However, health care providers who routinely provide screening options to their patients at average risk for CRC differ from the general population due to the nature of their work. Therefore, expecting the general population to adhere to CRC screening recommendations that health care providers themselves do not follow and trying to increase the CRC screening rates only through campaigns and national screening policies is unrealistic. We think that provider adherence to evidence-based guidelines for themselves and for their relatives as well as innovative strategies for improving CRC screening are crucial for achieving screening goals.

Despite the strength of a large sample size of general surgeons with a high response rate, several limitations need to be considered. First, the current study relied on self-reported data. Thus, reporting and recall bias is possible. Selection bias represents another potential limitation because the enrolled surgeons were selected from those surgeons who attended a national congress in Turkey. One other limitation is that the questionnaire contained 'closed-ended' questions. Last, the chosen threshold for high-volume surgeons was determined according to recent studies rather than nationwide surgical data.

\section{Conclusions}

Even general surgeons involved in the treatment of patients with CRC neglect to participate in CRC screenings, 
and the screening rate of their first-degree relatives is similar to that of the general population, i.e., not at the desired level. However, high-volume surgeons are more likely to undergo screening than low-volume surgeons. Because an increase in CRC screening rates largely depends on the efforts of health care providers, such as general surgeons, provider-related barriers to CRC screening need to be tackled to achieve acceptable screening rates.

\section{Additional file}

Additional file 1. Survey questions related to colorectal cancer screening behaviors of general surgeons and first-degree family members.

\section{Abbreviations}

ACS: American Cancer Society; CRC: Colorectal cancer; FOBT: Fecal occult blood test; Gl: Gastrointestinal; GP: General practitioner; USPSTF: US MultiSociety Task Force of Colorectal Cancer and US Preventive Services Task Force

\section{Acknowledgements}

Not applicable.

\section{Authors' contributions}

SUC, MAK, SE, CA: study design, statistical analysis, interpretation of the data, and manuscript drafting/revision. HGC, EB, Al, ENI, YC, YEY: data collection. SUC, HGC, MAK, CA: study concept and critical revision of the manuscript for important intellectual content. All authors have read and approved the manuscript.

\section{Funding}

The authors declare that they did not receive funding for this research from any source.

\section{Availability of data and materials}

The datasets generated and/or analyzed during the current study are not publicly available but are available from the corresponding author on reasonable request.

\section{Ethics approval and consent to participate}

This study was approved by the Ankara University School of Medicine Undergraduate Student Researches Ethics Committee (approval number: 72189195-050.03.04-E.6039). All patients provided their written informed consent and the study was carried out in accordance with the 1964 Helsinki Declaration and its later amendments.

\section{Consent for publication}

Written informed consent for publication of individuals' clinical details was obtained.

\section{Competing interests}

The authors declare that they have no competing interests.

\section{Author details}

${ }^{1}$ Department of General Surgery, Gulhane Training and Research Hospital, Ankara, Turkey. ${ }^{2}$ Department of General Surgery, Ankara University School of Medicine, Ankara, Turkey.

Received: 6 February 2019 Accepted: 31 October 2019

Published online: 12 November 2019

\section{References}

1. Rex DK, Boland CR, Dominitz JA, et al. Colorectal cancer screening: recommendations for physicians and patients from the U.S. multi-society task force on colorectal Cancer. Am J Gastroenterol. 2017;112:1016-30.
2. Bibbins-Domingo K, Grossman DC, Curry SJ, et al. Screening for colorectal cancer: US preventive services task force recommendation statement. JAMA 2016;315:2564-75.

3. Meester RG, Doubeni CA, Zauber AG, et al. Public health impact of achieving $80 \%$ colorectal cancer screening rates in the United States by 2018. Cancer. 2015:121:2281-5.

4. Karlitz JJ, Oliphant AB, Greenwald DA, et al. The American College of Gastroenterology and the $80 \%$ by 2018 colorectal cancer initiative: a multifaceted approach to maximize screening rates. Am J Gastroenterol. 2017;112:1360-2.

5. DeGroff A, Sharma K, Satsangi A, et al. Increasing colorectal cancer screening in health care systems using evidence-based interventions. Prev Chronic Dis. 2018:15:E100.

6. Smith RA, Andrews KS, Brooks D, et al. Cancer screening in the United States, 2018: a review of current American Cancer Society guidelines and current issues in cancer screening. CA Cancer J Clin. 2018:68:297-316.

7. Navarro M, Nicolas A, Ferrandez A, et al. Colorectal cancer population screening programs worldwide in 2016: an update. World J Gastroenterol. 2017;23:3632-42.

8. Altobelli E, D'Aloisio F, Angeletti PM. Colorectal cancer screening in countries of European council outside of the EU-28. World J Gastroenterol. 2016;22:4946-57.

9. Rim SH, Zittleman L, Westfall JM, et al. Knowledge, attitudes, beliefs, and personal practices regarding colorectal cancer screening among health care professionals in rural Colorado: a pilot survey. J Rural Health. 2009;25:303-8.

10. Tekiner AS, Lale G, Peker A, et al. The rates of undergoing cancer screening among family physicians aged 40 and older working in Ankara province. Konuralp Med J. 2016:8:118-23.

11. Buurma M, Kroon HM, Reimers MS, et al. Influence of individual surgeon volume on oncological outcome of colorectal cancer surgery. Int J Surg Oncol. 2015;2015:464570

12. Billingsley KG, Morris AM, Dominitz JA, et al. Surgeon and hospital characteristics as predictors of major adverse outcomes following colon cancer surgery: understanding the volume-outcome relationship. Arch Surg. 2007;142:23-32

13. Morris M, Platell CF. Surgical volume influences survival in patients undergoing resections for stage II colon cancers. ANZ J Surg. 2007;77:902-6.

14. Siegel RL, Miller KD, Fedewa SA, et al. Colorectal cancer statistics, 2017. CA Cancer J Clin. 2017:67:177-93.

15. Siegel RL, Miller KD, Jemal A. Cancer statistics, 2018. CA Cancer J Clin. 2018; 68:7-30.

16. Arnold M, Sierra MS, Laversanne M, et al. Global patterns and trends in colorectal cancer incidence and mortality. Gut. 2017;66:683-91.

17. Garborg K. Colorectal cancer screening. Surgical Clin North Am. 2015;95: 979-89.

18. Schreuders EH, Ruco A, Rabeneck L, et al. Colorectal cancer screening: a global overview of existing programmes. Gut. 2015:64:1637-49.

19. Lieberman D, Ladabaum U, Cruz-Correa M, et al. Screening for colorectal cancer and evolving issues for physicians and patients: a review. JAMA. 2016;316:2135-45

20. Knudsen AB, Zauber AG, Rutter CM, et al. Estimation of benefits, burden, and harms of colorectal cancer screening strategies: modeling study for the US preventive services task force. JAMA. 2016:315:2595-609.

21. Ponti A, Anttila A, Ronco G, et al. Cancer screening in the European Union. Report on the implementation of the council recommendation on cancer screening. France: European Commission; 2017.

22. Nadeau M, Walaszek A, Perdue DG, et al. Influences and practices in colorectal cancer screening among health care providers serving northern plains American Indians, 2011-2012. Prev Chronic Dis. 2016;13:E167.

23. Hilsden RJ, McGregor E, Murray A, et al. Colorectal cancer screening: practices and attitudes of gastroenterologists, internists and surgeons. Can J Surg. 2005:48:434-40.

24. Menees SB, Patel DA, Dalton V. Colorectal cancer screening practices among obstetrician/gynecologists and nurse practitioners. J Women's Health (Larchmt). 2009;18:1233-8.

25. Terhaar Sive Droste JS, Heine GD, Craanen ME, et al. On attitudes about colorectal cancer screening among gastrointestinal specialists and general practitioners in the Netherlands. World J Gastroenterol. 2006;12: 5201-4. 
26. Cai SR, Zhang SZ, Zhu HH, et al. Barriers to colorectal cancer screening: a case-control study. World J Gastroenterol. 2009;15:2531-6.

27. Shokar NK, Nguyen-Oghalai T, Wu H. Factors associated with a physician's recommendation for colorectal cancer screening in a diverse population. Fam Med. 2009:41:427-33.

\section{Publisher's Note}

Springer Nature remains neutral with regard to jurisdictional claims in published maps and institutional affiliations.

Ready to submit your research? Choose BMC and benefit from:

- fast, convenient online submission

- thorough peer review by experienced researchers in your field

- rapid publication on acceptance

- support for research data, including large and complex data types

- gold Open Access which fosters wider collaboration and increased citations

- maximum visibility for your research: over $100 \mathrm{M}$ website views per year

At BMC, research is always in progress.

Learn more biomedcentral.com/submissions 